\title{
Valve durability after transcatheter aortic valve implantation
}

\author{
Akash Kataruka, Catherine M. Otto \\ Division of Cardiology, University of Washington, Seattle, WA, USA \\ Contributions: (I) Conception and design: All authors; (II) Administrative support: None; (III) Provision of study materials or patients: None; (IV) \\ Collection and assembly of data: All authors; (V) Data analysis and interpretation: All authors; (VI) Manuscript writing: All authors; (VII) Final \\ approval of manuscript: All authors. \\ Correspondence to: Prof. Catherine M. Otto, MD. Division of Cardiology, University of Washington, Box 356422, 1959 NE Pacific Street, HSB \\ AA522, Seattle, WA 98195-6422, USA. Email: otto@cardiology.washington.edu.
}

\begin{abstract}
Transcatheter aortic valve implantation (TAVI) is a minimally invasive procedure to treat severe symptomatic aortic stenosis. While the TAVI procedure can be performed safely and provide excellent 5 -year results, little is known about long-term durability. TAVI valves are composed of bioprosthetic leaflets are prone to deterioration, which are categorized as structural valve deterioration (SVD) and nonSVD. SVD refers to an intrinsic pathology of the leaflets or stent structure with mechanisms that include leaflet calcification, leaflet tear, stent fracture, or stent creep. Non-SVD processes include valve thrombosis, infective endocarditis and patient prosthesis mismatch. TAVI valves degenerate by similar mechanisms as bioprosthetic surgical aortic valves. Unique mechanisms that contribute to TAVI degeneration include valve crimpling, balloon expansion, stent under-expansion and valve thrombosis. The absence of a universally accepted definition of SVD poses a challenge in estimating valve durability. Traditional surgical bioprosthetic aortic valves have demonstrated excellent durability with clinically relevant SVD of $6.6 \%$ at 10 -year follow up. Long-term durability of TAVI valves, however, remain poorly defined. From meta-analysis TAVI trials, SVD was estimated at $7 \%$ at 5 years. With iterative improvements in TAVI valve construction and deployment techniques, long-term durability may improve. Until long-term outcomes are better understood, TAVI should be used with caution in younger patients.
\end{abstract}

Keywords: Transcatheter aortic valve implantation durability (TAVI durability); aortic stenosis; structural valve deterioration; long-term outcomes; valve hemodynamics

Submitted Jun 26, 2018. Accepted for publication Jul 06, 2018.

doi: $10.21037 /$ jtd.2018.07.38

View this article at: http://dx.doi.org/10.21037/jtd.2018.07.38

\section{Introduction}

Surgical aortic valve replacement (SAVR) was previously the only effective method for relief of left ventricular outflow obstruction in adults with aortic valve stenosis. Transcatheter aortic valve implantation (TAVI) now offers an attractive alternative for treatment of severe symptomatic aortic stenosis in appropriately selected patients. Several randomized trials have established superiority of TAVI for the treatment of patients who have a prohibitive and high surgical mortality risk and as a reasonable alternative for older adults with an intermediate estimated surgical mortality risk (1-5). The weight of this evidence led to endorsement of TAVI in selected patients by multiple guidelines and rapid adoption in clinical practice (6-9). In fact, TAVI has replaced SAVR as the predominant method of treating aortic stenosis for patients over the age of 75 years. More importantly, the use of TAVI has increased markedly in younger patients (10-12), despite the lack of data on long-term valve durability. The concept of valve durability is especially important patients less than age 75 years at the time of valve implantation. Life expectancy is likely to exceed valve durability in many of these patients. The purpose of this article is to review the available literature related to TAVI durability, including the definitions and mechanisms of structural valve deterioration (SVD). 


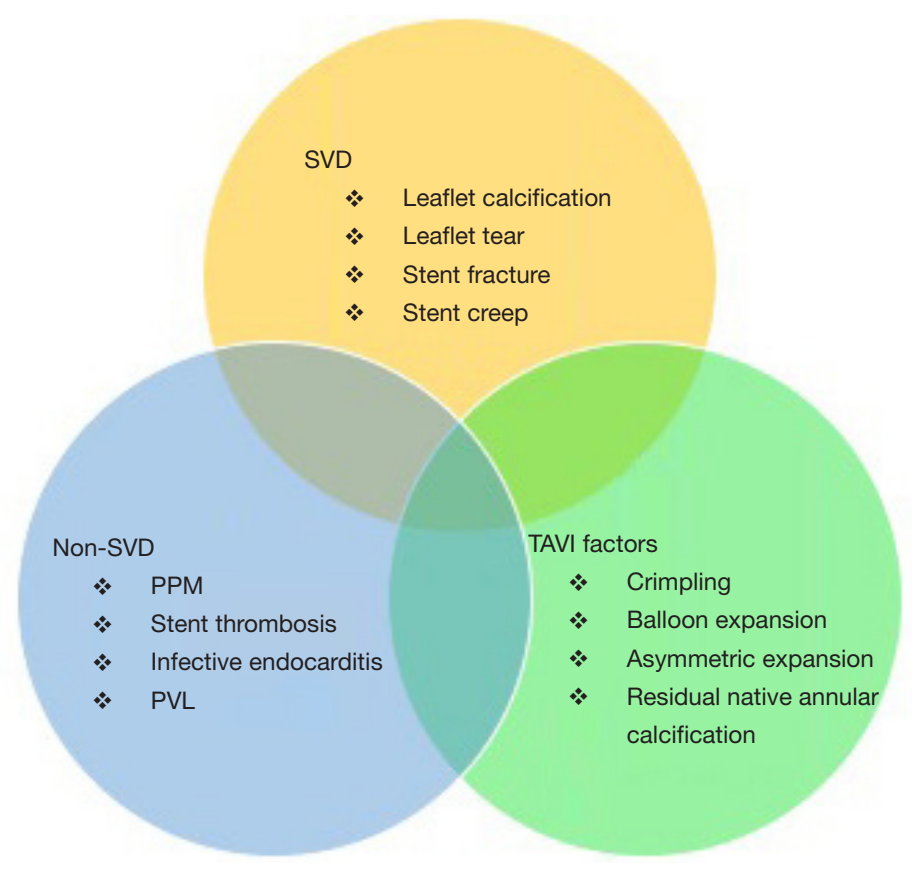

Figure 1 Mechanisms for bioprosthetic valve deterioration. SVD, structural valve deterioration; PPM, patient prosthesis mismatch; PVL, para-valvular regurgitation.

\section{Definition of SVD}

The use of bioprosthetic valves has increased steadily over the past decade and surpassed mechanical valves as the most common aortic valve prosthesis (13). In the United States, approximately $80 \%$ of SAVR is performed with a bioprosthetic implant (14). The shift towards biologic valves is likely multifactorial due to patient life-style preferences, avoiding the need for lifelong anticoagulation, and excellent durability of current generative surgical bioprosthetic valves. Although long-term outcomes are unproven, many patients and clinicians hope that transcatheter valve-in-valve treatment will be effective for eventual valve deterioration. The "Achilles heel" of all bioprosthetic valves, however, is SVD. The likelihood of SVD is very low for the first 10 years after SAVR in older adults with a gradual increase in incidence after that time $(15,16)$.

Guidelines for reporting outcomes of bioprosthetic valves classify valve dysfunction as SVD and non-SVD (Figure 1). SVD is defined as intrinsic degeneration or dysfunction of the prosthetic valve materials. The principal mediators of SVD include leaflet calcification, leaflet tear, stent fracture, or stent creep. Non-SVD refers to secondary processes that involve the valve such as patient-prosthesismismatch (PPM), valve leaflet thrombosis, endocarditis, pannus ingrowth or paravalvular leak. A post-operative echocardiogram after TAVI or SAVR is crucial to establish baseline imaging and hemodynamic measurements for future comparisons, particularly distinguishing PPM from SVD. It is important to keep in mind that SVD and nonSVD are not mutually exclusive processes. In particular, non-SVD mechanisms such as patient-prosthesis mismatch, leaflet thrombosis and paravalvular regurgitation have been associated with accelerated SVD due to altered valve hemodynamics and mechanical stress (17-19).

The largest challenge in defining SVD arises from the absence of a universally accepted criterion, which limits the ability to draw clear comparisons between studies. Society guidelines vary in the specific echocardiographic parameters used to define SVD (20-23). A recent consensus document defined progressive stages of SVD associated with recommended follow up and treatment for each stage (24).

\section{SAVR and TAVI durability}

The durability of TAVI will always be placed in context of bioprosthetic SAVR durability owing to the known long-term results with surgical prosthesis. In this regard, 
the incidence of SVD in the surgical literature is actually difficult to determine because freedom from valve reintervention is a common clinical end-point (25). This clinical end-point underestimates the true incidence of SVD because re-operation may not be offered to poor surgical candidates and some may die before echocardiographic detection of SVD.

The long-term durability of SAVR bioprosthesis has proven to be excellent. In a large cohort of 12,569 patients with Carpentier-Edwards valve, re-operation rate was $1.9 \%$ and $15 \%$ at 10 and 20 years, respectively. Independent predictors of SVD were young age ( $<60$ years), PPM and elevated post-operative trans-prosthetic gradient (26). Long-term echocardiographic and clinical outcomes were analyzed for 669 patients with varying SAVR models. In this cohort, $5.4 \%$ patients underwent aortic valve reintervention for SVD, $6.6 \%$ developed clinically relevant SVD and 30.1\% developed sub-clinical SVD (27). This study underscores the importance of both clinical and echocardiographic surveillance to detect SVD.

The durability of TAVI is less well defined compared to its surgical counterpart. Long-term results of selected publications are summarized in Table 1. Two studies identified a $23-\mathrm{mm}$ prosthesis as an independent risk factor for SVD $(32,33)$. This finding suggests that patientprosthesis mismatch may contribute to perturbed valve hemodynamics leading to accelerated SVD. A meta-analysis of 13 studies with 8,914 patients demonstrated a low overall incidence of SVD with a pooled estimate of 28 per 1,000 patient-years. SVD was estimated to $7 \%$ at 5 years, and only $12 \%$ of patients that developed SVD were treated with reintervention (40).

Robust data on TAVI durability extends only to five years, which falls short of the expected time frame when SAVR valves deteriorate (40). Until long-term durability is defined, TAVI valves should be used with caution in patients younger than the age of 75 at the time of implantation or patients with a long life-expectancy. Furthermore, bicuspid aortic valves (BAV) are more common in younger patients with severe aortic stenosis. TAVI durability is even less defined in the BAV patient population.

Interpretation of the TAVI literature warrants some discussion. First, there have been iterative improvements in stent technology, pre-procedure planning, deployment technique and operator experience which is expected to improve long-term durability for more recently implanted valves. Second, TAVI is frequently utilized in medicallycomplicated elderly patients who may die from non-cardiac causes and, therefore, SVD may go undetected. Finally, an annual surveillance echocardiogram is recommended postTAVI, which is more frequent than surgical prosthesis (41). As a result, non-clinically significant SVD may be detected more frequently on long-term follow up for TAVI. Surveillance echocardiograms should be standardized for TAVI and SAVR to allow for better comparison for SVD.

\section{Mechanisms of valve dysfunction}

Numerous patient specific factors have been implicated with accelerated SVD_including younger age, diabetes, hypertension, hyperparathyroidism, renal insufficiency, hyperparathyroidism, elevated proprotein convertase subtilisin/kexin 9 serum levels, and elevated apolipoprotein $\mathrm{B}$ /apolipoprotein A ratio (42). These factors have been implicated with SVD in surgical prothesis and also are expected to influence TAVI valve durability.

Prosthesis related factors affecting durability include mechanisms of SVD and non-SVD. The most common pathologic process is calcific degeneration as a result of repetitive mechanical stress. This process can lead to either stenosis, regurgitation or combined stenosis and regurgitation (43). Bovine aortic valves are prone to calcification and stenosis, whereas porcine valves develop tears leading to insufficiency (44). As a correlate, current balloon-expandable transcatheter valves are composed of bovine pericardial tissue and self-expanding valves are constructed from porcine pericardium. Furthermore, most commercially available TAVI prosthesis are treated with $0.6 \%$ glutaraldehyde to reduce the immunogenicity of the xenograft. However, glutaraldehyde treatment causes cellular level changes that promotes passive calcific deposition (42). Several anti-calcification strategies, such as 2-amino oleic acid, have been developed to inhibit leaflet calcification and the detrimental effects of glutaraldehyde $(45,46)$. Unfortunately, first generation TAVI prosthesis were not prepared with anti-mineralization treatment.

Infective endocarditis can cause early or late acute valve failure. The incidence of endocarditis is approximately $0.57 \%$ per person-year and is highest during the first year following implantation. Bioprosthetic valves are associated with higher risk of endocarditis than mechanical prosthesis (47). The incidence of endocarditis is higher at approximately $1.1 \%$ per person-year. Moderate to severe aortic regurgitation is the largest risk factor for developing endocarditis in TAVI patients (48). Leaflet trauma and sheer stress may increase the risk of endocarditis in this setting. 
Table 1 Summary of selected publications on long-term TAVI follow-up

\begin{tabular}{|c|c|c|c|c|}
\hline Study & Valve type & $\begin{array}{l}\text { Number of } \\
\text { patients }\end{array}$ & $\begin{array}{l}\text { Longest } \\
\text { follow up }\end{array}$ & Comments \\
\hline Mack et al. (28) & Edwards SAPIEN & 699 & 5 years & Reintervention: $0 \%$ \\
\hline Gerckens et al. (29) & CoreValve & 1,015 & 5 years & Reintervention: $1.2 \%$ \\
\hline \multirow{2}{*}{ Toggweiler et al. (30) } & \multirow{2}{*}{$\begin{array}{l}\text { Cribier-Edwards and } \\
\text { SAPIEN }\end{array}$} & \multirow{2}{*}{88} & \multirow{2}{*}{5 years } & SVD: $3.4 \%$ \\
\hline & & & & $\begin{array}{l}\text { AVA decreased by } 0.06 \mathrm{~cm}^{2} / \text { year and mean gradient increased } \\
0.27 \mathrm{mmHg} / \text { year }\end{array}$ \\
\hline \multirow[t]{2}{*}{ Barbanti et al. (31) } & \multirow[t]{2}{*}{ CoreValve ( $3^{\text {rd }}$ generation $)$} & \multirow[t]{2}{*}{353} & \multirow[t]{2}{*}{5 years } & Reintervention: $0.6 \%$ \\
\hline & & & & No significant change in valve hemodynamics \\
\hline \multirow[t]{2}{*}{ Del Trigo et al. (32) } & \multirow{2}{*}{$\begin{array}{l}\text { Edwards SAPIEN, Edwards } \\
\text { XT, CoreValve }\end{array}$} & \multirow[t]{2}{*}{1,521} & \multirow[t]{2}{*}{5 years } & SVD: $4.5 \%$ \\
\hline & & & & $\begin{array}{l}\text { Absence of anticoagulation, TViV, 23-mm valve and obesity } \\
\text { associated with SVD }\end{array}$ \\
\hline \multirow[t]{2}{*}{ Vemulapalli et al. (33) } & \multirow[t]{2}{*}{ Edwards and CoreValve } & \multirow[t]{2}{*}{10,099} & \multirow[t]{2}{*}{1 year } & SVD: $2.5 \%$ (increase in mean gradient $10 \mathrm{mmHg}$ ) \\
\hline & & & & $\begin{array}{l}\text { TViV, 23-mm valve, PPM, obesity and increasing gradient } \\
\text { predicted SVD }\end{array}$ \\
\hline Rodes-Cabau et al. (34) & $\begin{array}{l}\text { Cribier-Edwards, Edwards } \\
\text { SAPIEN, SAPIEN XT, }\end{array}$ & 339 & 42 months & Reintervention: 2 patients due to endocarditis \\
\hline & SAPIEN & & & SVD: $0 \%$ \\
\hline & & & & $\begin{array}{l}\text { Trans-prosthetic gradient increased mildly from } 10 \text { to } 12.1 \\
\mathrm{mmHg}(\mathrm{P}=0.03)\end{array}$ \\
\hline Holy et al. (37) & CoreValve & 152 & 8.9 years & Reintervention: $3.3 \%$ (due to PVL) \\
\hline & & & & SVD: $0 \%$ \\
\hline Muratori et al. (38) & Edwards SAPIEN, SAPIEN & 96 & 5 years & Reintervention: $0 \%$ \\
\hline & $\mathrm{XT}$ & & & SVD: $30 \%$ \\
\hline & & & & $\begin{array}{l}\text { Female gender, small BSA, } 23-\mathrm{mm} \text { prosthesis and low AVA } \\
\text { post-implantation predicted SVD }\end{array}$ \\
\hline Gilard et al. (39) & CoreValve, Edwards & 4,201 & 3.8 years & Reintervention: $0 \%$ \\
\hline & SAPIEN & & & SVD: $2 \%$ per year \\
\hline & & & & No significant change in valve hemodynamics \\
\hline
\end{tabular}


The advent of four-dimensional commuted tomography (4DCT) has drawn attention to leaflet immobility and subclinical valve thrombosis for both SAVR and TAVI prostheses. The incidence, diagnosis and clinical significance of this phenomenon is under active investigation. Definitive diagnosis requires findings on 4DCT with elevated trans-prosthetic gradients that resolve with therapeutic anticoagulation, or surgical visualization of thrombus (49). A pooled observational study from two large registries evaluated 890 patients with SAVR and TAVI prostheses. Subclinical valve thrombosis was found more commonly on TAVI prosthesis compared to SAVR (13\% vs. $4 \%, \mathrm{P}=0.001$ ). All 36 patients with valve thrombosis had resolution of elevated gradients with anticoagulation with either warfarin or direct oral anticoagulant. Importantly, elevated trans-prosthetic gradients $(>20 \mathrm{mmHg})$ was found more frequently in patients with reduced leaflet motion (6\% vs. 1\%, $\mathrm{P}=0.004)$ (50). Absence of anticoagulation has been associated with accelerated SVD, suggesting that valve thrombosis may be a pathologic process (32). Randomized control trials are underway to determine the optimal antithrombotic regimen post-TAVI. The underlying cause for the higher frequency of valve thrombosis in TAVI is unclear. Abnormal blood flow in the neo-sinus, divider between the TAVI frame and anatomical sinus, has been implicated as a potential mechanism (51).

Finally, PPM has been associated with increased mortality and accelerated SVD. The primary mode of SVD in patients with PPM is severe valve stenosis due to increased mechanical stress (17). TAVI is associated with lower rates of PPM and higher effective orifice areas (EOA) (52). This may in part explain the favorable outcomes associated with TAVI. Independent predictors of PPM in TAVI include lower BSA, smaller aortic annulus diameter, low ejection fraction, small indexed EOA (53). Special attention must be paid in the presence of these findings to minimize PPM.

\section{Unique mechanisms for TAVI}

In addition to factors that contribute to dysfunction of both surgical and transcatheter valves, several mechanisms unique to the TAVI delivery system might affect long-term durability.

First, the TAVI valve leaflets and frame are crimped prior to implantation to allow for transcatheter delivery. As a result, TAVI leaflets are designed to be much thinner than surgical bioprosthetic leaflets $(0.4 v s .0 .25 \mathrm{~mm})$. Electron microscopy analysis has demonstrated that crimped valves have structural damage due to altered collagen arrangement which might predispose to thrombus formation and accelerated calcification (54). With the decreasing size of TAVI delivery mechanisms and post-dilation, the effects of crimping may become further accentuated. The longterm clinical consequences of crimping remain unknown. Second, TAVI valves are mounted on a rigid frame and native annular calcification is not removed with TAVI which may lead to asymmetric expansion of the valve frame; both of which may lead to adverse leaflet-stent interactions. Bench testing has demonstrated increased leaflet stress, particularly on the commissure and stent-attachment (55). This pattern of leaflet stress differs substantially from SAVR leaflet stress. Third, valve thrombosis and reduced leaflet motion occurs more frequently with TAVI than SAVR. These findings are associated with elevated transprosthetic gradients (50). Fourth, TAVI frames are sometimes oversized to minimize the risk of paravalvular regurgitation. This results in under-expansion of the TAVI frame and altered mechanical stress on the leaflets (56). There is little data on the long-term durability of TAVI when used as a valve-in-valve procedure for patients with a failing aortic bioprosthesis (43). Finally, we might wonder whether the compressed native valve might still be biologically active, contributing to ongoing inflammation adjacent to the TAVI stent and leaflets.

\section{Conclusions}

The utilization of TAVI has increased dramatically over the past decade. While mid-term follow up studies demonstrate favorable outcomes, the long-term durability of TAVI remains unclear. Durability is particularly important in younger patients who are expected to outlive their TAVI prosthesis. TAVI valves deteriorate by similar mechanisms as surgical bioprosthesis. Unique aspects of TAVI such as crimpling, post-dilation, and asymmetric stent expansion may affect long-term durability.

\section{Acknowledgements}

None.

\section{Footnote}

Conflicts of Interest: The authors have no conflicts of interest to declare. 


\section{References}

1. Leon MB, Smith CR, Mack M, et al. Transcatheter aortic-valve implantation for aortic stenosis in patients who cannot undergo surgery. N Engl J Med 2010;363:1597-607.

2. Smith CR, Leon MB, Mack MJ, et al. Transcatheter versus surgical aortic-valve replacement in high-risk patients. N Engl J Med 2011;364:2187-98.

3. Leon MB, Smith CR, Mack MJ, et al. Transcatheter or Surgical Aortic-Valve Replacement in Intermediate-Risk Patients. N Engl J Med 2016;374:1609-20.

4. Reardon MJ, Van Mieghem NM, Popma JJ, et al. Surgical or Transcatheter Aortic-Valve Replacement in Intermediate-Risk Patients. N Engl J Med 2017;376:1321-31.

5. Adams DH, Popma JJ, Reardon MJ, et al. Transcatheter aortic-valve replacement with a self-expanding prosthesis. N Engl J Med 2014;370:1790-8.

6. Nishimura RA, O'Gara PT, Bonow RO. Guidelines Update on Indications for Transcatheter Aortic Valve Replacement. JAMA Cardiol 2017;2:1036-7.

7. Nishimura RA, Otto CM, Bonow RO, et al. 2017 AHA/ ACC Focused Update of the 2014 AHA/ACC Guideline for the Management of Patients With Valvular Heart Disease: A Report of the American College of Cardiology/ American Heart Association Task Force on Clinical Practice Guidelines. J Am Coll Cardiol 2017;70:252-89.

8. Baumgartner H, Falk V, Bax JJ, et al. 2017 ESC/EACTS Guidelines for the management of valvular heart disease. Eur Heart J 2017;38:2739-91.

9. Grover FL, Vemulapalli S, Carroll JD, et al. 2016 Annual Report of The Society of Thoracic Surgeons/American College of Cardiology Transcatheter Valve Therapy Registry. Ann Thorac Surg 2017;103:1021-35.

10. Reinohl J, Kaier K, Reinecke H, et al. Effect of Availability of Transcatheter Aortic-Valve Replacement on Clinical Practice. N Engl J Med 2015;373:2438-47.

11. Auffret V, Lefevre T, Van Belle E, et al. Temporal Trends in Transcatheter Aortic Valve Replacement in France: FRANCE 2 to FRANCE TAVI. J Am Coll Cardiol 2017;70:42-55.

12. Nguyen V, Michel M, Eltchaninoff $\mathrm{H}$, et al. Implementation of Transcatheter Aortic Valve Replacement in France. J Am Coll Cardiol 2018;71:1614-27.

13. Isaacs AJ, Shuhaiber J, Salemi A, et al. National trends in utilization and in-hospital outcomes of mechanical versus bioprosthetic aortic valve replacements. J Thorac Cardiovasc Surg 2015;149:1262-9.e3.

14. Brown JM, O'Brien SM, Wu C, et al. Isolated aortic valve replacement in North America comprising 108,687 patients in 10 years: changes in risks, valve types, and outcomes in the Society of Thoracic Surgeons National Database. J Thorac Cardiovasc Surg 2009;137:82-90.

15. Wang M, Furnary AP, Li HF, et al. Bioprosthetic Aortic Valve Durability: A Meta-Regression of Published Studies. Ann Thorac Surg 2017;104:1080-7.

16. Foroutan F, Guyatt GH, O'Brien K, et al. Prognosis after surgical replacement with a bioprosthetic aortic valve in patients with severe symptomatic aortic stenosis: systematic review of observational studies. BMJ 2016;354:i5065.

17. Flameng W, Herregods MC, Vercalsteren M, et al. Prosthesis-patient mismatch predicts structural valve degeneration in bioprosthetic heart valves. Circulation 2010;121:2123-9.

18. Doris MK, Dweck MR. Is bioprosthetic leaflet thrombosis a trigger to valve degeneration? Heart 2018;104:792-3.

19. Genereux P, Head SJ, Hahn R, et al. Paravalvular leak after transcatheter aortic valve replacement: the new Achilles' heel? A comprehensive review of the literature. J Am Coll Cardiol 2013;61:1125-36.

20. Zoghbi WA, Chambers JB, Dumesnil JG, et al. Recommendations for evaluation of prosthetic valves with echocardiography and doppler ultrasound: a report From the American Society of Echocardiography's Guidelines and Standards Committee and the Task Force on Prosthetic Valves, developed in conjunction with the American College of Cardiology Cardiovascular Imaging Committee, Cardiac Imaging Committee of the American Heart Association, the European Association of Echocardiography, a registered branch of the European Society of Cardiology, the Japanese Society of Echocardiography and the Canadian Society of Echocardiography, endorsed by the American College of Cardiology Foundation, American Heart Association, European Association of Echocardiography, a registered branch of the European Society of Cardiology, the Japanese Society of Echocardiography, and Canadian Society of Echocardiography. J Am Soc Echocardiogr 2009;22:975-1014; quiz 1082-4.

21. Capodanno D, Petronio AS, Prendergast B, et al. Standardized definitions of structural deterioration and valve failure in assessing long-term durability of transcatheter and surgical aortic bioprosthetic valves: a consensus statement from the European Association of 
Percutaneous Cardiovascular Interventions (EAPCI) endorsed by the European Society of Cardiology (ESC) and the European Association for CardioThoracic Surgery (EACTS). Eur J Cardiothorac Surg 2017;52:408-17.

22. Lancellotti P, Pibarot P, Chambers J, et al.

Recommendations for the imaging assessment of prosthetic heart valves: a report from the European Association of Cardiovascular Imaging endorsed by the Chinese Society of Echocardiography, the Inter-American Society of Echocardiography, and the Brazilian Department of Cardiovascular Imaging. Eur Heart J Cardiovasc Imaging 2016;17:589-90.

23. Kappetein AP, Head SJ, Genereux P, et al. Updated standardized endpoint definitions for transcatheter aortic valve implantation: the Valve Academic Research Consortium-2 consensus document. J Am Coll Cardiol 2012;60:1438-54.

24. Dvir D, Bourguignon T, Otto CM, et al. Standardized Definition of Structural Valve Degeneration for Surgical and Transcatheter Bioprosthetic Aortic Valves. Circulation 2018;137:388-99.

25. Anselmi A, Flecher E, Ruggieri VG, et al. Long-term results of the Medtronic Mosaic porcine bioprosthesis in the aortic position. J Thorac Cardiovasc Surg 2014;147:1884-91.

26. Johnston DR, Soltesz EG, Vakil N, et al. Long-term durability of bioprosthetic aortic valves: implications from 12,569 implants. Ann Thorac Surg 2015;99:1239-47.

27. Rodriguez-Gabella T, Voisine P, Dagenais F, et al. LongTerm Outcomes Following Surgical Aortic Bioprosthesis Implantation. J Am Coll Cardiol 2018;71:1401-12 .

28. Mack MJ, Leon MB, Smith CR, et al. 5-year outcomes of transcatheter aortic valve replacement or surgical aortic valve replacement for high surgical risk patients with aortic stenosis (PARTNER 1): a randomised controlled trial. Lancet 2015;385:2477-84.

29. Gerckens U, Tamburino C, Bleiziffer S, et al. Final 5-year clinical and echocardiographic results for treatment of severe aortic stenosis with a self-expanding bioprosthesis from the ADVANCE Study. Eur Heart J 2017;38:2729-38.

30. Toggweiler S, Humphries KH, Lee M, et al. 5-year outcome after transcatheter aortic valve implantation. J Am Coll Cardiol 2013;61:413-9.

31. Barbanti M, Petronio AS, Ettori F, et al. 5-Year Outcomes After Transcatheter Aortic Valve Implantation With CoreValve Prosthesis. JACC Cardiovasc Interv 2015;8:1084-91.
32. Del Trigo M, Munoz-Garcia AJ, Wijeysundera HC, et al. Incidence, Timing, and Predictors of Valve Hemodynamic Deterioration After Transcatheter Aortic Valve Replacement: Multicenter Registry. J Am Coll Cardiol 2016;67:644-55.

33. Vemulapalli S, Holmes DR Jr, Dai D, et al. Valve hemodynamic deterioration and cardiovascular outcomes in TAVR: A report from the STS/ACC TVT Registry. Am Heart J 2018;195:1-13.

34. Rodes-Cabau J, Webb JG, Cheung A, et al. Long-term outcomes after transcatheter aortic valve implantation: insights on prognostic factors and valve durability from the Canadian multicenter experience. J Am Coll Cardiol 2012;60:1864-75.

35. Ussia GP, Barbanti M, Petronio AS, et al. Transcatheter aortic valve implantation: 3 -year outcomes of selfexpanding CoreValve prosthesis. Eur Heart J 2012;33:969-76.

36. Gurvitch R, Wood DA, Tay EL, et al. Transcatheter aortic valve implantation: durability of clinical and hemodynamic outcomes beyond 3 years in a large patient cohort. Circulation 2010;122:1319-27.

37. Holy EW, Kebernik J, Abdelghani M, et al. Long-term durability and hemodynamic performance of a selfexpanding transcatheter heart valve beyond 5 years after implantation: A prospective observational study applying the standardized definitions of structural deterioration and valve failure. EuroIntervention 2018. [Epub ahead of print].

38. Muratori M, Fusini L, Tamborini G, et al. Five-year echocardiographic follow-up after TAVI: structural and functional changes of a balloon-expandable prosthetic aortic valve. Eur Heart J Cardiovasc Imaging 2018;19:389-97.

39. Gilard M, Eltchaninoff H, Donzeau-Gouge P, et al. Late Outcomes of Transcatheter Aortic Valve Replacement in High-Risk Patients: The FRANCE-2 Registry. J Am Coll Cardiol 2016;68:1637-47.

40. Foroutan F, Guyatt GH, Otto CM, et al. Structural valve deterioration after transcatheter aortic valve implantation. Heart 2017;103:1899-905.

41. Otto CM, Kumbhani DJ, Alexander KP, et al. 2017 ACC Expert Consensus Decision Pathway for Transcatheter Aortic Valve Replacement in the Management of Adults With Aortic Stenosis: A Report of the American College of Cardiology Task Force on Clinical Expert Consensus Documents. J Am Coll Cardiol 2017;69:1313-46.

42. Cote N, Pibarot P, Clavel MA. Incidence, risk factors, 
clinical impact, and management of bioprosthesis structural valve degeneration. Curr Opin Cardiol 2017;32:123-9.

43. Dvir D, Webb JG, Bleiziffer S, et al. Transcatheter aortic valve implantation in failed bioprosthetic surgical valves. JAMA 2014;312:162-70.

44. Arsalan M, Walther T. Durability of prostheses for transcatheter aortic valve implantation. Nat Rev Cardiol 2016;13:360-7.

45. Chen W, Schoen FJ, Levy RJ. Mechanism of efficacy of 2-amino oleic acid for inhibition of calcification of glutaraldehyde-pretreated porcine bioprosthetic heart valves. Circulation 1994;90:323-9.

46. Clark JN, Ogle MF, Ashworth P, et al. Prevention of calcification of bioprosthetic heart valve cusp and aortic wall with ethanol and aluminum chloride. Ann Thorac Surg 2005;79:897-904.

47. Glaser N, Jackson V, Holzmann MJ, et al. Prosthetic Valve Endocarditis After Surgical Aortic Valve Replacement. Circulation 2017;136:329-31.

48. Regueiro A, Linke A, Latib A, et al. Association Between Transcatheter Aortic Valve Replacement and Subsequent Infective Endocarditis and In-Hospital Death. JAMA 2016;316:1083-92.

49. Holmes DR, Mack MJ. Aortic Valve Bioprostheses: Leaflet Immobility and Valve Thrombosis. Circulation 2017;135:1749-56.

Cite this article as: Kataruka A, Otto CM. Valve durability after transcatheter aortic valve implantation. J Thorac Dis 2018;10(Suppl 30):S3629-S3636. doi: 10.21037/jtd.2018.07.38
50. Chakravarty T, Sondergaard L, Friedman J, et al. Subclinical leaflet thrombosis in surgical and transcatheter bioprosthetic aortic valves: an observational study. Lancet 2017;389:2383-92.

51. Midha PA, Raghav V, Sharma R, et al. The Fluid Mechanics of Transcatheter Heart Valve Leaflet Thrombosis in the Neosinus. Circulation 2017;136:1598-609.

52. Tuzcu EM, Ozkan A, Kapadia SR. Prosthesis-patient mismatch in the transcatheter aortic valve replacement era. J Am Coll Cardiol 2011;58:1919-22.

53. Liao YB, Li YJ, Jun-Li L, et al. Incidence, Predictors and Outcome of Prosthesis-Patient Mismatch after Transcatheter Aortic Valve Replacement: a Systematic Review and Meta-analysis. Sci Rep 2017;7:15014.

54. Alavi SH, Groves EM, Kheradvar A. The effects of transcatheter valve crimping on pericardial leaflets. Ann Thorac Surg 2014;97:1260-6.

55. Sun W, Li K, Sirois E. Simulated elliptical bioprosthetic valve deformation: implications for asymmetric transcatheter valve deployment. J Biomech 2010;43:3085-90.

56. Salaun E, Zenses AS, Evin M, et al. Effect of oversizing and elliptical shape of aortic annulus on transcatheter valve hemodynamics: An in vitro study. Int J Cardiol 2016;208:28-35. 